\title{
Leitura e Discurso
}

\author{
REAding AND Discours
}

\section{Célia Bassuma FERNANDES *}

Resumo: Apesar dos inúmeros investimentos feitos na área da educação, seja no âmbito nacional ou estadual, constantemente, os meios de comunicação vêm divulgando dados alarmantes sobre o "caos" em que se encontra a educação brasileira. Neste trabalho, retomamos os documentos oficiais que buscam (re)direcionar o ensino de Língua Portuguesa, bem como refazemos, à luz de diferentes teorias, o percurso histórico da passagem dos estudos da frase para os estudos do texto, até chegarmos à Análise de Discurso de linha francesa, buscando demonstrar como essa "teoria da interpretação" pode contribuir para com o ensino de língua materna.

Palavras-chave: Texto; Discurso; Leitura.

Abstract: Despite the innumerous investments in education, either at the national or at the state level, the mass media have constantly published alarming data about the "chaos" in which the Brazilian education is found. In this work, we return to the official documents that seek to (re) direct the teaching of Portuguese as well as we retrace a historical path from the passage of the studies of the phrase to the studies of the text in light of different theories, until we finally get to the Discourse Analysis, of French affiliation, to demonstrate how it can contribute to the teaching of the mother tongue.

Key-words: Text; Discours; Reading.

* Doutoranda em Estudos da Linguagem na Universidade Estadual de Londrina. Docente da Universidade Estadual do Centro-Oeste. Contato: bacelfer@yahoo.com.br. 


\section{Introdução}

Não são raras as publicações em revistas e em outros meios de comunicação relatando a situação educacional premente em que se encontra o Brasil. Em Abril de 2010, a revista Veja (edição 2160) publicou uma reportagem ressaltando a urgência de se investir numa educação que qualifique os brasileiros para contribuírem com o crescimento econômico do país. Gustavo Ioschpe, autor da matéria, descreve a situação em que uma secretária virtual (profissional que presta serviços a partir de um escritório remoto, isto é, sem que seja necessário o contato com o contratante e seu deslocamento para o ambiente físico) teria confundido "cônsul brasileiro" com a marca Cônsul de eletrodomésticos e a cidade de Houston com um dos produtos fabricados pela mesma empresa ou mesmo pela Brastemp, por não compreender o enunciado que lhe pedia para conseguir a "informação de contato do cônsul brasileiro em Houston".

Diante de tal equívoco, o jornalista afirma que o Brasil está à beira de "ser um colosso em termos de crescimento econômico e esquecer a formação de sua gente". Enveredando por este caminho, diz ele, nossa pátria torna-se sua própria inimiga, pois o aumento da demanda por qualificação profissional/técnica choca-se com a incapacidade das escolas de formar cidadãos competentes. Para o autor, o atraso educacional brasileiro teria aumentado consideravelmente em relação aos países desenvolvidos. Como evidência, aponta uma pesquisa sobre alfabetização feita em 2009, pelo Instituto Paulo Montenegro, a qual indica que somente $25 \%$ dos brasileiros conseguem ler e entender um texto, ou seja, são plenamente alfabetizados, ou ainda, para usar um termo mais recente nos meios acadêmicos, são "letrados", isto é, capazes não somente de ler e escrever, mas de responder às exigências da linguagem nas relações interpessoais, posicionando-se e interagindo socialmente.

Do nosso ponto de vista, essa incapacidade de o sujeito interpretar o que lê, indica que há uma grande deficiência nas aulas de Língua Portuguesa que, mais uma vez, instiga os interessados, em especial, os professores, a repensar o processo de ensino-aprendizagem da língua materna, que, infelizmente, ainda hoje, apesar de tantos esforços e salvo raras exceções, ainda tem como ponto de partida o ensino da metalinguagem, ou seja, o ensino voltado para as normas gramaticais. 
Neste trabalho, propomo-nos a tratar dos documentos oficiais que oferecem parâmetros, diretrizes para a educação nacional, detendonos naqueles referentes ao ensino de Língua Portuguesa (daqui em diante LP). Em seguida, refazemos o percurso sobre como se deu a passagem dos estudos da frase para o estudo do texto, abordando algumas teorias como a Linguística Textual e a Teoria da Enunciação, até chegarmos à Análise do Discurso de orientação francesa, entendida como uma "teoria da leitura", observando como ela pode contribuir para a prática da leitura em língua materna.

\section{Os documentos oficiais: os Parâmetros Curriculares Nacionais (PCNs) e as Diretrizes Curriculares Estaduais para a Educação Básica (DCEs)}

Como sabemos, o processo de industrialização e de urbanização do Brasil iniciado na década de 60, do século XX, teve como uma de suas conseqüências, o acesso de um enorme contingente de filhos de trabalhadores provenientes das classes populares aos bancos escolares. Nessa época, o ensino de LP, ainda pautado no ensino das regras da variedade dita "culta" da língua ainda se mostrava eficaz, tendo em vista que os alunos que até então freqüentavam a escola falavam uma variedade que dela se aproximava. Além disso, essa variedade condizia com a que era oferecida pelas gramáticas tradicionais e também pelos manuais didáticos em voga. A tão propalada "crise" que teria se instaurado no ensino de LP e que perdura até hoje, segundo especialistas, teria sido então, decorrente da chegada desse novo público às instituições de ensino e do embate que se estabelece entre a variedade linguística ensinada nas escolas e usada pelas elites, e aquela(s) trazida(s) por essa grande massa de filhos das classes trabalhadoras.

No final da década de 60 e início da de 70, começam a surgir propostas para a reformulação do ensino de língua materna que levavam em conta o modo de ensinar, mas não consideravam os conteúdos a serem efetivamente ensinados. Como sabemos, a prática educativa dominante desde o início dos anos 70, de caráter conteudista, encontrava-se pautada nas teorias linguísticas tributárias ao estruturalismo saussureano e na Teoria da Comunicação. A primeira entendia a língua como um sistema fechado de signos e a outra, como "instrumento de 
comunicação", ambas deixando de lado fatores extralinguísticos, como, por exemplo, a história e as circunstâncias nas quais os discursos eram produzidos.

$\mathrm{Na}$ década de 80, pesquisadores de algumas Universidades, Secretarias de Educação dos Estados e educadores, reuniram-se com o objetivo de propor mudanças na forma de compreender a linguagem, bem como no processo de ensino-aprendizagem. No Paraná, tais discussões resultaram na publicação do Currículo para a Educação Básica, no ano de 1990, e, em âmbito nacional, em 1998, nos PCNs (Parâmetros Curriculares Nacionais), documento publicado pelo MEC, com base na Lei de Diretrizes e Bases da Educação Nacional (Lei Federal n 9394 , de 20/12/96), que chamam à atenção para o fato de que os índices de repetência estavam relacionados à dificuldade que a escola apresentava não só em alfabetizar, mas também de garantir o uso eficaz da linguagem em todos os níveis. O objetivo do documento era o de servir como uma referência curricular nacional que inspirasse às diversas regiões, respeitando as diferenças, propostas educacionais que garantissem aos alunos o acesso aos conhecimentos básicos, mantendo a unidade do ensino das diferentes disciplinas e contribuindo com os profissionais da educação na elaboração de propostas didáticas.

De acordo com o documento, o termo "parâmetro" foi usado porque comunica a ideia de que, ao mesmo tempo em que deveriam ser respeitadas as peculiaridades regionais, culturais e políticas existentes no país, fossem construídas referências nacionais que pudessem delimitar quais pontos comuns caracterizariam o ensino da língua materna no país. Para tanto, toma o texto como objeto de ensino e propõe que o trabalho com a língua seja pautado nos diversos gêneros textuais, a fim de que o aluno tenha contato com a grande variedade de textos que circulam socialmente, possibilitando que ele seja capaz não apenas de "decifrá-los", mas de compreendê-los. Enfatiza, ainda, que só se aprende a língua produzindo textos e discursos, e que a sala de aula de Língua Portuguesa é um lugar privilegiado para essa produção. Ou seja, de acordo com o documento, as atividades escolares devem ser desenvolvidas a partir de contextos significativos que favoreçam ao aluno a análise crítica, levando-o a identificar além de pontos de vista e valores, também eventuais preconceitos veiculados nos diferentes discursos. 
Tomando por base as linguísticas textuais e discursivas, o documento propõe um ensino centrado em três eixos: a- Prática e escuta de textos orais e leitura de textos escritos; b- Prática de produção de textos orais e escritos; c- Prática de análise linguística. Conforme as diretrizes, as atividades curriculares devem pautar-se na prática ininterrupta:

[...] de escuta de textos orais e leitura de textos escritos e de produção de textos orais e escritos, que devem permitir, por meio da análise e reflexão sobre os múltiplos aspectos envolvidos, a expansão e construção de instrumentos que permitam ao aluno, progressivamente, ampliar sua competência discursiva. (PCNs/LP, 1998, p. 27)

Entendendo a linguagem como atividade discursiva, o documento elege o texto como unidade de ensino e ressalta que as atividades gramaticais devem levar em conta o conhecimento que o aluno tem da sua própria língua. Propõe ainda, que o ensino de LP não se reduza ao trabalho com a gramática normativa, mas que seja centrado em atividades reflexivas sobre a própria linguagem, possibilitando não apenas pensar nos diferentes procedimentos lingüístico-discursivos usados pelo autor do texto e que refletem as condições de produção do discurso, mas também nas restrições impostas pelo gênero e pelo suporte no qual circulam.

Com relação à prática pedagógica, os $\operatorname{PCNs}$ (1998, p. 27) apontam para a criação de situações que possibilitem aos alunos a trabalharem com a própria linguagem, "desvendando", ao longo dos vários anos, as peculiaridades da fala da sua comunidade, dando especial atenção às similaridades e às diferenças de formas e de usos lingüísticos, de modo a construir hipóteses sobre as condições contextuais e estruturais nas quais elas se dão. Segundo o documento, é a partir desse trabalho com os diferentes tipos de textos lidos ou ouvidos, que os alunos poderão descrever os aspectos observados e entender a língua

[...] como um sistema de signos específico, histórico e social, que possibilita a homens e mulheres significar o mundo e a sociedade. Aprendê-la é aprender não somente palavras e saber 
combiná-las em expressões complexas, mas apreender pragmaticamente seus significados culturais e, com eles, os modos pelos quais as pessoas entendem e interpretam a realidade e a si mesmas. (PCNs/LP, 1998, p. 20)

Em suma, os PCNs alertam sobre a necessidade de se considerar a "linguagem como atividade discursiva, o texto como unidade de ensino e a noção de gramática como relativa ao conhecimento que o falante tem de sua linguagem" (PCNs/LP,1998, p.27). Ainda de acordo com o documento, a atividade discursiva é determinada pelas condições de produção, as quais levam o sujeito do discurso a fazer escolhas a partir de suas finalidades e intenções

[...] dos conhecimentos que acredita que o interlocutor possua sobre o assunto, do que supõe serem suas opiniões e convicções, simpatias e antipatias, da relação de afinidade e do grau de familiaridade que têm (sic), da posição social e hierárquica que ocupam” (PCNs/LP,1998, p. 21).

Atreladas aos esforços do governo federal, surgem, no estado do Paraná, as Diretrizes Curriculares de Língua Portuguesa para a Educação Básica (DCEs), que circularam em duas versões: a primeira - impressa em 2005 - foi enviada aos professores da rede pública estadual, para que propusessem sugestões de reformulação, e a segunda - versão eletrônica (2008) - utilizada para os propósitos desse trabalho, pode ser encontrada no portal Dia-a-dia-Educação, mantido pela SEED/Pr. Convém ressaltar que, embora haja diferenças e semelhanças nas duas versões com relação ao ensino-aprendizagem de LP, ambas têm por objetivo (re)discutir os pressupostos teóricos e metodológicos que norteiam a disciplina.

Tal como o anterior, esse documento também salienta que, tradicionalmente, o ensino de língua materna encontra-se pautado no repasse de regras e no ensino da nomenclatura da gramática tradicional, e que essa concepção de cunho normativista, ao trabalhar com palavras e frases isoladas, acaba por deixar de lado a história, o sujeito e o contexto de produção nos quais os discursos são produzidos (DCEs, 2008, p. 48-49). Propõe, assim, que a linguagem seja trabalhada sob 
uma concepção que não entende a língua como um sistema organizado de signos, mas como forma de interação social, ou seja, que a linguagem seja entendida como fenômeno social, uma vez que nasce da necessidade de interação dos homens.

Ancorado nos pressupostos teóricos desenvolvidos por Mikhail Bakhtin, bem como nos de seus seguidores, o documento entende a linguagem como um fenômeno social cuja origem está na necessidade de interação (política, social, econômica) entre os homens. É nesse processo de interação social que a palavra significa, o que implica dizer que os homens não recebem a língua pronta. De acordo com essa concepção, ao ensinar a língua materna, devem ser observados os aspectos sociais e históricos nos quais o sujeito está inserido, bem como o contexto de produção dos enunciados orais e/ou escritos, uma vez que os seus significados são sociais e historicamente construídos.

Desse modo, cabe à escola possibilitar aos seus alunos, a efetiva participação nas diferentes práticas sociais - entendidas como toda atividade humana exercida com e na linguagem - e que utilizem a leitura, a escrita e a oralidade com a finalidade de interagirem socialmente. As DCEs salientam, ainda, que todos os que frequentam a escola pública devem ser inseridos nessa sociedade marcada por conflitos sociais, raciais, religiosos e políticos, entre outros, marcando, assim, suas vozes (e vez!!!!), no contexto nos quais estão inseridos.

De acordo com as diretrizes, o ensino-aprendizagem de língua materna tem por objetivo aprimorar os conhecimentos linguísticos e discursivos dos alunos, a fim de que eles possam compreender e interagir com os discursos que circulam socialmente. Para isso, é relevante que "a língua seja percebida como uma arena em que diversas vozes sociais se defrontam, manifestando diferentes opiniões" (DCEs, 2008, P. 50), e cabe à escola possibilitar ao aluno o contato com uma grande variedade de textos, permitindo-lhe envolver-se nas práticas de uso da língua, sejam elas de leitura, de oralidade ou de escrita.

Segundo o documento, o conceito de texto não envolve apenas a efetivação dos discursos verbais ou não-verbais, mas o evento que abrange o antes e o depois da sua formulação, isto é, as condições da sua produção, bem como os efeitos de sentido que produzem em seu interlocutor. Conforme Bakhtin (1999), os discursos são o resultado da articulação de textos, de vozes que se materializam, da linguagem 
em uso efetivo. Assim, um texto não é um objeto fixo num dado momento do tempo, mas é sempre uma atitude responsiva diante de outros textos, com os quais estabelece relações dialógicas.

Para que tal proposta seja atingida, o documento aponta como objetivos norteadores do processo de ensino: a necessidade de mostrar ao aluno as possibilidades de emprego da língua, isto é, de saber adequála a cada contexto e a cada interlocutor e que o professor - mediador da aprendizagem - tenha claro por que e para quê deve trabalhar com uma ampla variedade de gêneros textuais.

Tendo em vista a concepção de linguagem como discurso que se efetiva nas diferentes práticas sociais apresentada pelas diretrizes, o processo de ensino-aprendizagem na disciplina de língua materna, busca, no que se refere à leitura: "analisar os textos produzidos, lidos e/ou ouvidos, possibilitando que o aluno amplie seus conhecimentos linguístico-discursivos" (DCEs, 2008, p. 54). Assim, deve-se ter claro que, quanto maior for o contato com os diferentes tipos de texto nas diferentes esferas sociais, mais possibilidades há de entendê-lo, bem como os seus sentidos, suas intenções e visões de mundo, uma vez que “a ação pedagógica referente à linguagem, precisa pautar-se na interlocução, em atividades planejadas que possibilitem ao aluno a leitura e a produção oral e escrita, bem como a reflexão e o uso da linguagem em diferentes situações" (DCEs/LP, 2008, p.55).

No documento em questão, a leitura é entendida como "um ato dialógico, interlocutivo, que envolve demandas sociais, políticas, econômicas, pedagógicas e ideológicas de determinado momento" (DCEs/LP, 2008, p. 56). Concebendo a linguagem como prática que se efetiva nas diferentes instâncias sociais e a língua como um acontecimento social intimamente ligada aos seus falantes, e, portanto, perpassada por valores ideológicos, elege o discurso como conteúdo estruturante, isto é, como o conjunto de saberes e de conhecimentos que organizam uma disciplina, e o concebe como "prática social", ou seja, como "o resultado da interação - oral e escrita - entre sujeitos". No entanto, sinaliza para o fato de que tanto o uso língua como o discurso são constituídos por enunciados orais ou escritos, produzidos por um sujeito que é responsável por aquilo que fala e/ou escreve, e para quem a localização geográfica, temporal, social ou etária é elemento essencial na constituição dos discursos. Assim, nas aulas de LP, a língua 
deverá ser trabalhada a partir da linguagem em uso -dimensão dada pelo Conteúdo Estruturante (o discurso) - considerando-se os diversos gêneros discursivos que circulam socialmente (DCEs/LP, 2008, p. 63).

\section{A passagem dos estudos da frase para os estudos do texto}

A percepção de que há múltiplas maneiras de significar despertou em muitos estudiosos uma nova forma de se relacionar com a linguagem. A noção de texto é bem antiga e remonta aos clássicos romanos que se preocupavam com a arte do "bem falar" e do "bem escrever" (oratória e retórica). A partir da Renascença, os estudiosos voltam seus interesses para as regras fonéticas, morfológicas e sintáticas, pois conforme Indursky (2006, p. 38), o declínio do latim e o surgimento da Gramática de Port-Royal (1775/1783), de Lancelot e Arnauld, na França, e da Gramática Philosófica da Lingua Portuguesa:princípios da gramática geral applicados a nossa linguagem, de Soares Barbosa, em Portugal, tinham como objetivo único, a descrição das línguas neolatinas,e, por conseguinte, para a aprendizagem das regras da língua, resultando no apagamento do texto, nessa época entendido como a combinação de sílabas, palavras e de frases.

Essa visão limitada de ensino da língua é decorrente, como sabemos, do corte epistemológico promovido por Ferdinand de Saussure, no séc. XX, o qual institui a língua como objeto de estudo da Linguística, e considera o texto como parte da atividade linguageira do sujeito, mas o deixa de fora dos estudos linguísticos. Esse trato ou (des)trato com o texto perpassou o trabalho dos estruturalistas e dos gerativistas, embora estudiosos como Jakobson e Hjemslev já apontem para uma ruptura com os padrões até então vigentes, seja entendendo a língua como instrumento de comunicação e incluindo o locutor no funcionamento da linguagem, ou propondo-se a trabalhar não só com a língua, mas com a linguagem, incluindo assim, a reflexão sobre o texto.

Apesar disso, de acordo com Indursky, esses autores continuaram a entender a língua como sistema fechado e o texto como extensão da teoria da língua. Segundo ela, esse modo de entender a língua e o texto perdura até as décadas de 50/60 do séc. passado, quando ocorre uma grande divisão entre os linguistas sobre o objeto de estudo da 
Linguística. De um lado, um grupo começa a sinalizar para o texto e para sua constituição, dando origem à Linguística Textual, cuja primeira fase, denominada transfrástica, entende o texto como prolongamento da frase, pois objetiva compreendê-lo a partir das regularidades que a transcendem, sem, no entanto, abandonar os estudos frasais. Numa época posterior, tem início a fase denominada gramática do texto, que buscava ultrapassar os limites da frase e entender o texto como um todo, partindo da sua descrição (constituição, coesão e coerência, textualidade e formas de delimitação). Essa forma de se relacionar com o texto possibilitou que se passasse naturalmente das relações internas das frases para as relações internas do texto, o qual começa a ser considerado como a maior unidade linguística de análise.

Posteriormente, os estudiosos dessa vertente teórica voltam-se não apenas para as relações de coesão e coerência (relação interna) do texto, mas também passam a concebê-lo como um ato de comunicação, como uma unidade pragmático-comunicativa, isto é, acreditam que as intenções do autor são instruções a serem decodificadas pelo leitor para que o sentido textual seja alcançado. Conforme Indursky (2006, p. 49), esses "jogos de atuação comunicativa" dão origem a uma abordagem psicolinguística da leitura, na medida em que compreende a língua como um código que deve ser decodificada pelo leitor. No desenvolvimento da teoria, são estabelecidos sete critérios para que um texto possa assim ser considerado. Os dois primeiros, de natureza semântica e formal, dão conta da textualidade, possibilitando afirmar que um texto é um texto. Desse modo, entende que a coesão é a relação de dependência que se estabelece entre as frases, e a coerência, o fator fundamental da textualidade, resultado da lógica interna do texto.

Os outros fatores, apesar de desempenharem um papel importante, não são primordiais para a construção da textualidade do texto, e remetem para as suas qualidades pragmáticas: a- intencionalidade: diz respeito ao efeito que o locutor pretende desencadear no seu interlocutor, o leitor: b- aceitabilidade: é o extremo oposto do primeiro, pois se de um lado o locutor pretende desencadear determinados efeitos no leitor, de outro, este deve aceitar as instruções que lhe permitem decodificar o texto; c- situacionalidade: refere-se à pertinência e relevância do texto em relação ao contexto em que é produzido; d- informatividade: 
refere-se ao grau de informação nova veiculada pelo texto; eintertextualidade: diz respeito à relação que um texto estabelece com outros.

Cabe salientar que, de acordo com a Linguística Textual, os termos texto e discurso são utilizados como sinônimos, e que a noção de discurso, proveniente de outro campo do conhecimento, é inserida no arcabouço teórico dessa disciplina, mas não é submetida a nenhuma teorização. Mesmo assim, apesar das lacunas e questões em aberto, cabe à Linguística Textual o mérito da "passagem dos estudos da frase para os estudos do texto".

Nesse mesmo período, surge também a Teoria da Enunciação para a qual o texto equivale ao enunciado, que, por sua vez, remete imediatamente para a enunciação. Ao encaminhar os estudos do texto para além dos estudos da frase, Benveniste nega a concepção de língua como sistema fechado de signos e a existência de uma sintaxe textual, passando assim a considerar não apenas a significação, mas também o contexto situacional e o sujeito falante. Para ele, esses fatores exteriores ao texto e deixados de lado pelas outras teorias linguísticas vigentes na época, influenciam de modo inequívoco na sua compreensão. Assim, para o fundador da teoria da enunciação, na língua

[...] há aquele que fala, o locutor, o EU, e aquele a quem o locutor se dirige, o interlocutor, o TU. E este locutor está necessariamente situado em um contexto de situação que determina o tempo da enunciação (aqui) e o espaço da enunciação (agora), ou seja, a enunciação supõe sempre os interlocutores e está datada e situada no espaço (INDURSKY, 2006, p.53, grifos da autora).

No Brasil, seguindo essa mesma vertente, Eduardo Guimarães propõe que o texto seja estudado como uma operação enunciativa, a partir das suas relações internas, sem, no entanto, deixar de lado os fatores extralingüísticos. Substituindo a noção de coerência pela de consistência, afirma que colocar o texto em relação com a sua exterioridade significa submetê-lo à interpretação, à exterioridade que lhe é constitutiva e, por conseguinte, ao interlocutor, o que implica passar do contexto linguístico para o situacional. De acordo com ele, para se chegar ao sentido do texto não basta apenas decodificar as 
relações coesivas que se estabelecem na superfície textual, no contexto linguístico, mas passar pelo contexto situacional, isto é, por uma operação que envolve o locutor e o interlocutor, pelo viés da consistência, ou seja, remetê-lo às relações que convocam à interpretação desse texto com o acontecimento enunciativo em que ele foi produzido.

Também buscando inserir nas análises aquilo que havia sido excluído, ainda na década de 1960, do século XX, surge, na França, com Michel Pêcheux, a Análise de Discurso (AD). Edificada sob á égide do Materialismo Histórico, da Linguística e da Psicanálise, esse dispositivo teórico tem por objetivo romper com as teorias que buscavam atravessar o texto para responder à pergunta: "O que esse texto quer dizer?" ou "Quais são as principais ideias contidas nesse texto?”

\section{Leitura do ponto de vista da $\mathrm{AD}$}

Ao conceber o texto como o lugar onde o discurso adquire uma forma material, e este como o efeito de sentido entre interlocutores, a teoria materialista do discurso busca ir além das análises de conteúdo cujo objetivo era "extrair" os sentidos do texto, deslocando a questão: "o que este texto quer dizer" para "como este texto significa" (ORLANDI, 1999, p. 26). Para tanto, estuda a língua fazendo sentido, ou seja, leva em conta quem disse e por que disse, bem como as circunstâncias em que o dizer é produzido.

Partindo do pressuposto de que a ideologia adquire uma "forma encarnada" no discurso, cuja materialidade específica é a língua, a AD trabalha a relação língua-discurso-ideologia, relação essa que se complementa pelo fato de que como nos ensina Pêcheux (1997), a condição essencial para a existência do discurso é o sujeito, interpelado pela ideologia e atravessado pelo inconsciente. Podemos dizer, então, que a grande contribuição da AD para os estudos da linguagem é o de fornecer um dispositivo teórico que permite compreender como os objetos simbólicos produzem sentido "para e por sujeitos" (ORLANDI, 1999, p.17). Em síntese, a teoria materialista do discurso é uma teoria da interpretação, que visa compreender como um texto, definido por Orlandi (2001, p. 21) como "[...] a unidade complexa de significação, consideradas as condições de sua produção”, significa. 
Para esse aparato teórico, o texto não é fechado em si mesmo, nem tampouco pode ser considerado uma sucessão de palavras ou de frases. A proposta da Análise de Discurso é determinar o processo e as condições em que os discursos são produzidos, levando em conta a junção do simbólico (linguístico) e do imaginário (ideológico), a partir da relação que se estabelece entre a língua, o sujeito e o discurso.

As condições de produção do discurso compreendem, portanto, o contexto imediato, as circunstâncias da enunciação e o contexto sóciohistórico e ideológico em que o discurso foi produzido. Insere-se também aí, o interdiscurso, isto é, a memória, os já-ditos e esquecidos, os quais determinam os novos discursos. É a noção de interdiscurso, que permite compreender que os discursos são produzidos num continuum, ou seja, eles sempre retomam outros, conforme enfatiza Pêcheux:

[...] o processo discursivo não tem, de direito, início: o discurso se conjuga sempre sobre um discurso prévio, ao qual ele atribui o papel de matéria-prima, e o orador sabe que quando evoca tal acontecimento, que já foi objeto de discurso, ressuscita no espírito dos ouvintes o discurso no qual este acontecimento era alegado, com as "deformações" que a situação presente introduz e da qual pode tirar partido (PÊCHEUX, 1997b, p. 77)

É essa memória discursiva, o interdiscurso, o já-dito, que age sem a permissão do sujeito e permite o significado outro, os deslizamentos de sentido, apontando para outras leituras possíveis, e sinalizando para o fato de que as palavras, expressões, proposições recebem seu sentido da formação discursiva na qual os sujeitos se inscrevem, isto é, elas mudam de sentido segundo as posições sustentadas por aqueles que as empregam. Para Pêcheux (1997a, p. 161), “os indivíduos são 'interpelados’ em sujeitos do seu discurso pelas formações discursivas, por ele definidas como aquilo que pode/deve ou não pode/não deve ser dito a partir de uma posição numa dada conjuntura, e representam 'na linguagem' as formações ideológicas que lhes são correspondentes". Isso significa que as palavras "tiram" seu sentido dessas posições, isto é, em relação às formações ideológicas, nas quais essas posições se encontram inscritas. 
Cabe lembrar, que para a teoria materialista do discurso, esses sujeitos aos quais nos referimos, não são organismos biológicos ou seres individualizados no mundo, mas lugares determinados na estrutura de uma formação social, e que se encontram representados nos processos discursivos. Assim, não são os sujeitos físicos que funcionam no discurso, mas suas imagens que resultam de projeções, e que lhes permitem passar da situação definida objetivamente, para a posição (representações dessas situações).

Voltando à questão do sentido, para a $\mathrm{AD}$, a linguagem é opaca, incompleta, ou seja, por detrás das palavras há sempre outras palavras, outros sentidos, impossibilitando trabalhar a relação linguagem/ pensamento/mundo de forma direta, o que implica afirmar que não há sentidos dados a priori, pois eles são constituídos/administrados por sujeitos inscritos na história num processo simbólico. Desse modo, conforme Orlandi (2007, p. 52), não são as palavras que significam em si, mas o texto, por ela concebido como uma peça de linguagem, como uma unidade significativa. Enquanto objeto histórico, isto é, enquanto discurso (memória), ele estabelece relações não só com o contexto, mas também com outros textos, e com outros discursos.

Para Orlandi (2007, p. 9), a interpretação “está sempre presente em toda e qualquer manifestação da linguagem". Ela constitui uma exigência, ou nos termos da autora, há uma "injunção" à interpretação, uma vez que, diante de qualquer objeto simbólico, o sujeito, ainda que não se dê conta, é convocado a interpretar, a dar-lhe sentido. Conforme a autora, "não há sentido sem interpretação", e embora ele pareça ser literal, evidente, há sempre espaço para o equívoco, para a falha, para o deslize, para os outros sentidos.

Logo, ao tratar o texto como espaço significante no qual os sentidos são produzidos, a AD abre espaço para os gestos de interpretação, entendidos por Pêcheux como "atos no nível simbólico" (PÊCHEUX, 1997c, p. 84). Para Orlandi (1999, p.78), o gesto de interpretação do sujeito é determinado pelo funcionamento da ideologia, que provoca nele a ilusão de que a linguagem é transparente e de que os sentidos são evidentes, uma vez que ele se encontra inscrito em dada formação discursiva e não em outra. Assim, "ele não reconhece o movimento da interpretação, ao contrário, ele se reconhece nele. Ou melhor, se reconhece nos sentidos que produz". Isso significa 
que, embora o dispositivo ideológico seja inato ao sujeito, os sentidos não estão soltos, ao contrário, são controlados, pois vêm carregados de uma memória que, embora seja apagada, faz parecer que o sentido só pode ser aquele. É por isso que a $\mathrm{AD}$, ao interrogar a interpretação, confirma seu caráter ideológico, ou seja, afirma que a interpretação "se dá de um lugar da história e da sociedade e tem uma direção, que é o que chamamos de política. Desse modo, sempre é possível apreender a textualização do político" (Orlandi, 2007. p. 18).

Investir no trabalho de leitura, levando em conta os dispositivos teóricos da $\mathrm{AD}$, comporta, portanto, o entendimento de que a língua é um sistema sujeito a falhas, ao equívoco, afetada pela história que a faz significar. De acordo com Orlandi (2001, p.12), "ler é saber que o sentido pode ser outro". Esse entendimento faz retornar no interior do trabalho com a linguagem, o sujeito e a história, ou seja, ao se considerar os fatores extralinguísticos do texto, retornam elementos constitutivos que haviam sido excluídos por várias teorias linguísticas. Como afirma Orlandi (2007, p. 32), a linguagem, "não precisa, nem inteira, nem clara, nem direta", passa a ser entendida como discurso, objeto social marcado por aspectos linguísticos e históricos, que não podem ser separados no processo de constituição e de produção do sujeito do discurso e dos sentidos que (o) significam.

\section{Considerações finais}

A partir dessas considerações, é possível abordar a questão da leitura para a AD. De acordo Orlandi (2001, p. 35), a "leitura é uma questão lingüística, pedagógica e social ao mesmo tempo”, uma vez que não se deve absolutizar a perspectiva teórica a partir da qual se encara a leitura. A autora afirma também, que "toda leitura tem sua história" (ORLANDI, 2001, p. 41), pois fenômenos de variação, como o da leitura de classe, podem levar a leituras previstas de um texto, sem, contudo, fechá-lo a outras leituras possíveis. Podemos dizer, então, que, para a $\mathrm{AD}$, toda leitura implica na produção de efeitos de sentidos que se estabelecem a partir da relação com o contexto histórico-social, cultural, ideológico que envolve o texto, o autor e o leitor

É mister considerar, ainda, sob as afirmações de Orlandi (2001, p.9), que na leitura, de acordo com a perspectiva discursiva, estabelece- 
se uma relação de confronto entre o leitor virtual - resultante das antecipações que o autor faz dele por meio do mecanismo das formações imaginárias - e o leitor real, comprovando que ele não interage com o texto, mas com outros sujeitos históricos, sociais, ideológicos. Isso leva a autora a afirmar que "a leitura é o momento crítico da produção da unidade textual, da sua realidade significativa. É nesse momento que os interlocutores se identificam como interlocutores e, ao fazê-lo, desencadeiam o processo de significação do texto". Logo, para ela, a leitura é o processo em que sujeitos e sentidos se constituem simultaneamente (ORLANDI, 2001, p. 10).

Portanto, podemos afirmar que a contribuição da Análise de Discurso é valiosa para que o ensino de Língua Portuguesa possa corresponder às propostas dos Documentos Oficiais, sejam eles em âmbito nacional ou regional. Mais que isso, a Análise de Discurso enquanto teoria da interpretação, teoria da leitura, poderá contribui para a formação de sujeitos leitores se forem consideradas as condições de produção do texto, tanto em sentido estrito como amplo, e que incluem, portanto, os sujeitos, a situação, o contexto sócio-histórico, ideológico e também a memória, o interdiscurso, que disponibiliza os dizeres e atestam o pertencimento do sujeito à dada formação discursiva, na medida em que professor e alunos possam ressignificar sentidos já estabelecidos, institucionalizados.

Por fim, assinalamos que o "conteúdo curricular" não deve ser tomado como produto pronto, acabado, mas como passível de transformações a partir da concretização de práticas que permitam entender a forma como a ideologia se materializa na língua, por meio de discursos produzidos por sujeitos que a todo o momento são convocados, instados, a interpretar. Para tanto, não se pretende que os protagonistas do processo ensino-aprendizagem (professor e alunos) tornem-se analistas do discurso, tampouco, que os dispositivos teóricos da AD sejam usados como método em sala de aula.

Visa-se que não se trabalhe apenas com a estrutura da língua, mas com a língua como lugar de relações, sujeita a falhas, que significa na história, ou seja, com a prática discursiva, mostrando que os sentidos “não brotam das palavras" (ORLANDI, 2007, p. 99). Isso requer que o professor saiba problematizar a relação do aluno com o texto, para que ele, progressivamente, perceba como este se constitui e significa, 
pois como afirma Orlandi (2001, p. 11): “saber ler é saber o que o texto diz e o que ele não diz, mas o constitui significativamente".

Vale lembrar, ainda, que para a teoria materialista do discurso, o texto, unidade de análise, comporta diferentes leituras, já que ao considerar os fatores externos à língua ultrapassam-se os seus limites e trabalha-se com as condições nas quais ele é produzido, levando em conta não apenas as circunstâncias de enunciação, mas também, e principalmente, os sujeitos historicamente determinados, interpelados pela ideologia e atravessados pelo inconsciente.

Nas aulas de Língua Portuguesa, faz-se imprescindível então, que o professor tenha em mente que o aluno e ele próprio são sujeitos ideologicamente marcados, historicamente constituídos, escapando, assim, da análise de conteúdo, ou seja, da ilusão de que se pode atravessar o texto, a fim de auscutar-lhe um único sentido, pois como dissemos, para a teoria materialista do discurso, a linguagem é opaca e os sentidos sempre podem ser outros, uma vez que ela está aberta para a deriva, para o equívoco. Logo, o texto segue aberto, ainda que, por vezes, regulado, no caso da escola, pela ideologia do Estado.

\section{Referências}

BRASIL. Parâmetros Curriculares Nacionais. Linguagens, códigos e suas tecnologias. Brasília: Ministério da Educação/Secretaria de Educação Média e Tecnológica, 1998.

DCE - Diretrizes Curriculares da Educação Fundamental da Rede de Educação Básica do Estado do Paraná (versão eletrônica). Disponível em: < bttp.// wnw.diaadiaeducacao.pr.gov.br/.../diretrizes.../lingua_portuguesa.pdf>. Acesso em: 04/06/2010.

INDURSKY, F. O Texto Nos Estudos da Linguagem: Especificidades e Limites. In: ORLANDI, E; LAGAZZI-RODRIGUES, S. Discurso e Textualidade. Campinas/SP: Pontes, 2006.

LUNARDELLI, M. G. As diretrizes Curriculares para o Ensino Fundamental do Estado do Paraná - Lingua Portuguesa à luz do Interacionismo Sócio-Discursivo. 
Disponível em: < http://mmw3.unisul.br/paginas/ensino/pos/linguagem/cd/ Port/97.pdf.> Acesso em: 04/06/2010.

ORLANDI, E. Análise de Discurso: Princípios e Procedimentos. Campinas/ SP: Pontes, 1999.

Discurso e leitura. São Paulo: Cortez; Campinas: UNICAMP, 2001.

. Interpretação; autoria, leitura e efeitos do trabalho simbólico. Campinas/ SP: Pontes, 2007.

PÊCHEUX, M. Análise Automática do Discurso (AAD-69). In: GADET, F. e HAK, T. Por uma Análise Automática do Discurso: Uma Introdução à Obra de Michel Pêcheux. Campinas/SP: Editora da Unicamp, 1997 a, p. 61-151.

. O Discurso: Estrutura ou Acontecimento. Campinas/SP: Pontes, 1997b. 